\title{
Laparoscopy versus mini-laparotomy peritoneal catheter insertion of ventriculoperitoneal shunts: a systematic review and meta-analysis
}

\author{
Mingliang He, MD, Leping Ouyang, MD, Shengwen Wang, PhD, Meiguang Zheng, MD, and \\ Anmin Liu, PhD \\ Department of Neurosurgery, Sun Yat-Sen Memorial Hospital, Sun Yat-Sen University, Guangzhou, China
}

OBJECTIVE Ventriculoperitoneal (VP) shunt treatment is the main treatment method for hydrocephalus. The traditional operative approach for peritoneal catheter insertion is mini-laparotomy. In recent years, laparoscopy-assisted insertion has become increasingly popular. It seems likely that use of an endoscope could lower the incidence of shunt malfunction. However, there is no consensus about the benefits of laparoscopy-assisted peritoneal catheter insertion.

METHODS A systematic search was performed using the PubMed, Embase, ScienceDirect, and Cochrane Library databases. A manual search for reference lists was conducted. The protocol was prepared according to the interventional systematic reviews of the Cochrane Handbook, and the article was written on the basis of the PRISMA (Preferred Reporting Items for Systematic Reviews and Meta-Analysis) guidelines.

RESULTS Eleven observational trials and 2 randomized controlled trials were included. Seven operation-related outcome measures were analyzed, and 3 of these showed no difference between operative techniques. The results of the meta-analysis are as follows: in the laparoscopy group, the rate of distal shunt failure was lower (OR $0.41,95 \% \mathrm{Cl}$ $0.25-0.67 ; p=0.0003)$, the absolute effect is $7.11 \%$ for distal shunt failure, the number needed to treat is $14(95 \% \mathrm{Cl}$ 8-23), operative time was shorter (mean difference [MD], $-12.84 ; 95 \% \mathrm{Cl}-20.68$ to $-5.00 ; p=0.001$ ), and blood loss was less (MD $-9.93,95 \% \mathrm{Cl}-17.56$ to $-2.31 ; p=0.01)$. In addition, a borderline statistically significant difference tending to laparoscopic technique was observed in terms of hospital stay (MD $-1.77,95 \% \mathrm{Cl}-3.67$ to $0.13 ; p=0.07$ ).

CONCLUSIONS To some extent, a laparoscopic insertion technique could yield a better prognosis, mainly because it is associated with a lower distal failure rate and shorter operative time, which would be clinically relevant.

http://thejns.org/doi/abs/10.3171/2016.5.FOCUS1637

KEY WORDS hydrocephalus; laparoscopy; mini-laparotomy; ventriculoperitoneal shunt; meta-analysis

$\mathrm{H}$ YDROCEPHALUS is a common disease that is treated by neurosurgeons. ${ }^{2}$ First described in 1908, ventriculoperitoneal (VP) shunt placement remains a mainstay of surgical therapy for hydrocephalus. ${ }^{2}$ Over time, advances in design and materials of catheters as well as valves have been achieved. However, complications associated with VP shunts are still common. Typical complications include infection, malposition, dislocation, and obstruction. According to Patwardhan and Nanda, the overall annual health care costs associated with VP shunts in the US exceeds $\$ 1.1$ billion. ${ }^{27}$ Notably, distal complications account for as much as $30 \%$ of overall complications. ${ }^{16}$ Thus, a properly working peritoneal catheter is very important for successful VP shunt treatment. The distal insertion technique may play an important role in the occurrence of complications. Currently, a distal catheter is inserted using a variety of techniques, including minilaparotomy and laparoscopy. The most frequently used approach for shunt insertion remains the mini-laparotomy. ${ }^{37}$ However, it has been reported that the distal catheter failure rate associated with mini-laparotomy ranges from $6 \%$ to $28.7 \%,{ }^{18,28}$ which seems to be higher than that for laparoscopy (0\%-15.7\%). 1,5,6,9,13,20,35,37 Moreover, many studies have reported that patients undergoing laparoscopy benefit more from the shorter operative time, shorter hospital stay, and quicker recovery. 7,24 Many analyses account for the benefits. One of the most important reasons is that, with the laparoscopic method, surgeons are able to place the peritoneal portion of the VP shunt in the peritoneal cavity and confirm its efficiency under direct vision., ${ }^{7,23}$

ABBREVIATIONS MD = mean difference; NNT = number needed to treat; $R C T=$ randomized controlled trial; VP = ventriculoperitoneal. 
Overall, although many prospective and retrospective studies, RCTs, and case reports regarding the efficacy of the laparoscopic technique have been published, these studies have not reached a consensus. It is therefore the aim of this systematic review and meta-analysis to evaluate the efficacy of the laparoscopic method compared with the mini-laparotomy method from the included RCTs and cohort studies up to July 2015.

\section{Methods}

Before conducting this systematic review and metaanalysis, we developed a detailed protocol that included literature search strategies, inclusion and exclusion criteria, outcome measurements, selection and data extraction, quality assessment, and methods of statistical analysis. The protocol was prepared according to the Cochrane Handbook for Systematic Reviews of Interventions, and the study was written according to PRISMA (Preferred Reporting Items For Systematic Reviews and Meta-Analyses) guidelines. ${ }^{12}$

\section{Literature Search Strategy}

A literature search of laparoscopic and mini-laparotomy techniques for VP shunt placement was performed by 2 reviewers (L.O. and M.H.) on articles published between January 1993 and July 2015. A computerized search of the PubMed, Embase, ScienceDirect, and Cochrane Library databases was performed without restriction on the language of publication. Keyword and free text searches used combinations of the following keywords: laparoscopy, ventriculoperitoneal shunt, and hydrocephalus. A manual search for unpublished results of ongoing trials and presentations at significant scientific meetings was conducted as a supplement. All reference sections of eligible studies and pertinent reviews were hand-reviewed for potentially relevant studies. When a study generated multiple publications, the most current report was used.

\section{Literature Screening}

The decision on whether a study should be included was made independently by 2 authors (S.W. and M.Z.), and disagreements were settled by the senior author (A.L.).

The inclusion criteria were as follows: 1) all available RCTs and comparative studies (cohort studies: prospective and retrospective) that compared the laparoscopic method and mini-laparotomy method for all age groups; 2) need for a VP shunt for the treatment of hydrocephalus; and 3) the percentage or crude data explicitly reported for both the laparoscopic and mini-laparotomy methods.

The exclusion criteria were as follows: 1) insufficient data or the lack of a comparison group; 2) substantial imbalance of clinical characteristics (age, sex, race, and American Society of Anesthesiologists Physical Status class) or the absence of baseline information; and 3) editorials, letters, review articles, case reports, and animal experimental studies.

\section{Data Extraction and Quality Assessment}

The primary outcomes were overall shunt failure rate, distal shunt failure rate, overall infection rate, and intraop- erative complication rate. The secondary outcomes were operative time, hospital stay, and blood loss. Shunt failure is defined as any catheter-related problem that required a return to surgery for management, such as shunt malfunction, displacement, misplacement, malposition, dislocation, and obstruction. Intraoperative complication was defined as accidental injuries to viscera during operation. Studies were rated for the level of evidence according to criteria of the Centre for Evidence-Based Medicine in Oxford and by using the GRADE tool (GRADEpro, version 3.2 for Windows). The quality of the RCTs was evaluated according to the Cochrane Collaboration's tool, and bias was assessed using the method mainly established by Higgins et al..$^{12}$

\section{Statistical Analysis}

A meta-analysis was performed on the included studies using the software package RevMan (version 5.0, Cochrane Informatics \& Knowledge Management Department). Dichotomous variables are presented as ORs (laparoscopic vs mini-laparotomy) with 95\% CIs. Random-effect models were used, with significance set at $p<0.05$. In addition, for outcomes that showed statistically significant treatment effects, we calculated absolute risk reduction and number needed to treat (NNT). NNT was calculated using the absolute numbers and estimated using the control group event rate and OR with 95\% CI obtained from the metaanalysis. Statistical heterogeneity was assessed using the $\mathrm{I}^{2}$ statistic, which describes the proportion of total variation that is attributable to differences among trials rather than sampling error. An $\mathrm{I}^{2}$ value of $<25 \%$ was defined to represent low heterogeneity, a value between $25 \%$ and $50 \%$ was defined as moderate heterogeneity, and $>50 \%$ was defined as high heterogeneity between studies. Otherwise, the fixed-effects model was used. Moreover, a sensitivity analysis was performed when the heterogeneity was high to find out the source of heterogeneity. Funnel plots were used to screen for potential publication biases.

\section{Results}

Figure 1 shows a flow diagram according to the PRISMA statement, ${ }^{22}$ with the total number of citations retrieved using the search strategy and the number included in the systematic review. Thirteen studies met all of the inclusion criteria and were included in the analysis. In total, these studies included 3235 patients, of whom 1485 underwent laparoscopic-assisted VP shunt placement and 1750 underwent mini-laparotomy method-assisted VP shunt placement. Of these included studies, 2 are $\mathrm{RCTs}^{6,33}$ and 11 are cohort studies. ${ }^{3,4,7,8,23,24,26,29,31,32,40}$ As shown in Fig. 2, the quality of the RCTs was evaluated using the Higgins classification. ${ }^{11}$ A total of 13 studies were included for meta-analysis, and the sample size ranged from 22 to 810 . The percentage of included males ranged from $36.4 \%$ to $56.7 \%$, and the mean age of study patients ranged from 47 to 63.6 years; the groups were not significantly different with respect to age and sex. The characteristics of these studies are presented in Table 1. For the various definitions of the outcome measures existing in the included studies, it is necessary to describe the definitions (Table 2). 


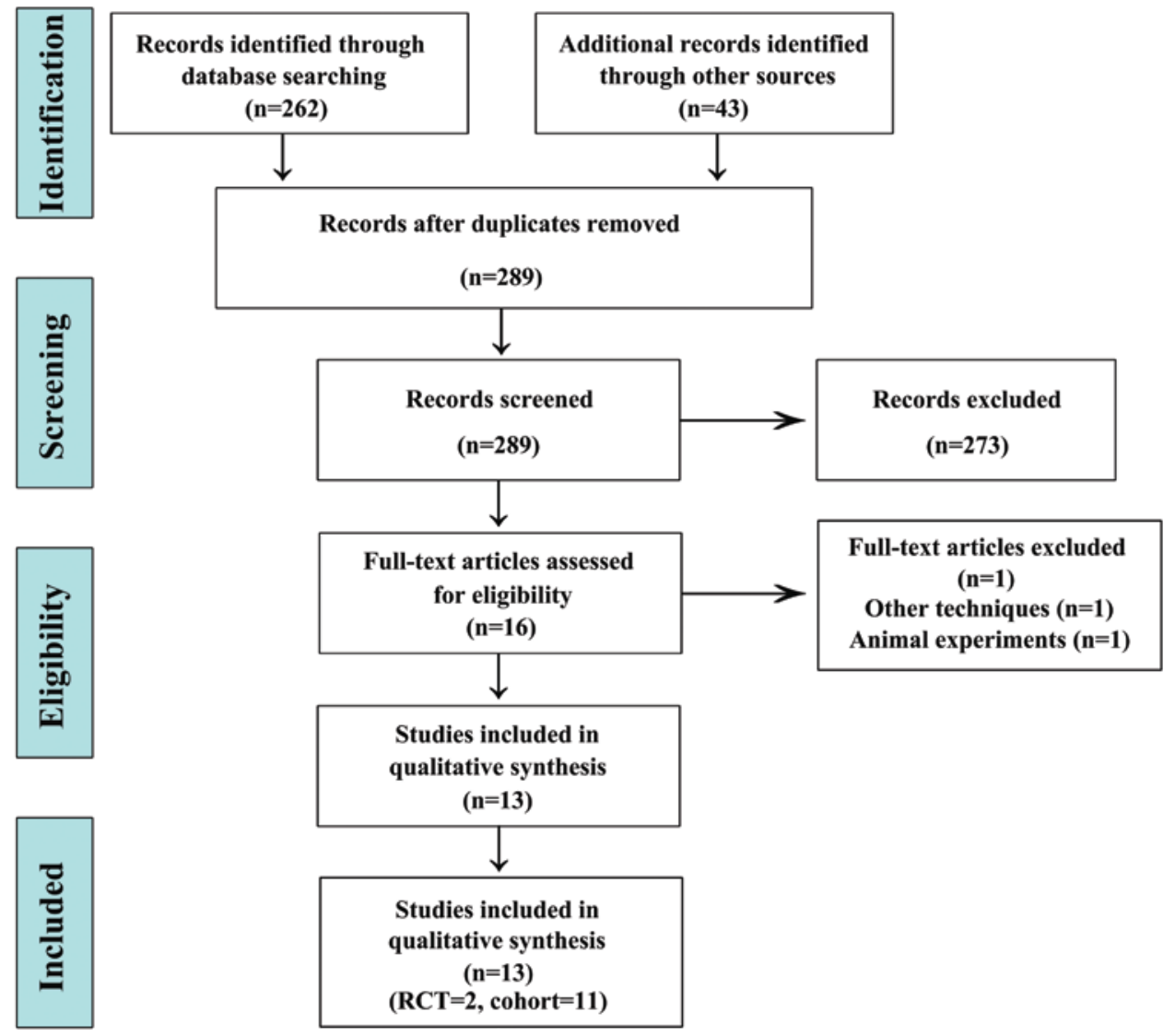

FIG. 1. PRISMA flow diagram of the systematic literature search.

\section{Primary Outcomes: Overall Shunt Failure, Distal Shunt Failure, Overall Infection, and Intraoperative Complications}

Eight studies $3,7,8,23,24,26,29,33$ that investigated the incidence of overall shunt failure after VP shunt surgery or revision were included in the meta-analysis, providing a total of 2279 patients. Results showed that there was no statistically significant difference between the two groups for overall shunt failure (laparoscopic vs mini-laparotomy: $17.5 \%$ vs $20.7 \%$ [OR $0.93,95 \%$ CI $0.73-1.18$; $\mathrm{p}=$ $0.53])$. Thirteen studies $3,4,6-8,23,24,26,29,31-33,40$ that investigated the incidence of distal shunt failure after VP shunt procedures or distal revisions were included for meta-analysis, with a total of 3219 patients. Studies showed that laparoscopy was associated with a less frequent occurrence of distal shunt failure (distal shunt failure rate for laparoscopy vs mini-laparotomy: $3.0 \%$ vs $10.2 \%$ [OR $0.41,95 \%$ CI $0.25-0.67 ; \mathrm{p}=0.0003]$ ), the absolute effect between groups was $7.11 \%$, and the NNT for 1 patient to prevent 1 shunt failure was 14 (95\% CI 8-23). The overall infection rate was reported in 10 studies $^{3,4,6,7,23,24,26,31-33}$ comprising a total of 2761 patients, and meta-analysis was performed to calculate the pooled rate of overall infection. The studies revealed no statistically significant difference between laparoscopy and mini-laparotomy with respect to overall infection rate $(6.5 \%$ vs $8.2 \%$ [OR $0.93,95 \%$ CI $0.60-1.43$; $\mathrm{p}=0.73])$. The incidence of intraoperative complications occuring during VP shunt procedures or distal revisions was reported for 1832 patients in 6 studies $^{3,23,26,29,31,33}$ and was used for meta-analysis. No statistically significant difference between laparoscopy and mini-laparotomy was observed $(0.9 \%$ vs $1.0 \%$ [OR $1.43,95 \%$ CI $0.55-3.69 ; \mathrm{p}=$ 0.46]) (Fig. 3).

\section{Secondary Outcomes: Operative Time, Hospital Stay, and Blood Loss}

Nine studies $3,4,6,7,23,24,26,32,33$ including a total of 2550 patients reported the length of operative time. The studies showed a significant difference between laparoscopy and mini-laparotomy (mean difference [MD] $-12.8,95 \%$ CI -20.68 to $-5.00 ; p=0.001$ ). For 6 studies $^{3,6,7,23,24,33}$ with a total of 2089 patients, the pooled length of hospital stay was calculated. There is a borderline statistically significant difference in favor of laparoscopy between the treatment groups $(\mathrm{MD}-1.77,95 \% \mathrm{CI}-3.67$ to $0.13 ; \mathrm{p}=0.07)$. Pooling the data from 2 studies $^{3,23}$ that assessed the blood loss in 1389 patients showed that laparoscopy was associated with better outcomes compared with mini-laparotomy (MD -9.93, 95\% CI -17.56 to -2.31 ; $\mathrm{p}=0.01$ ) (Fig. 4).

Of this meta-analysis, the summary of the pooled outcome measure and their quality are shown in Table 3 . Results of the sensitivity analysis showed that no significant difference was observed when eliminating the studies one 


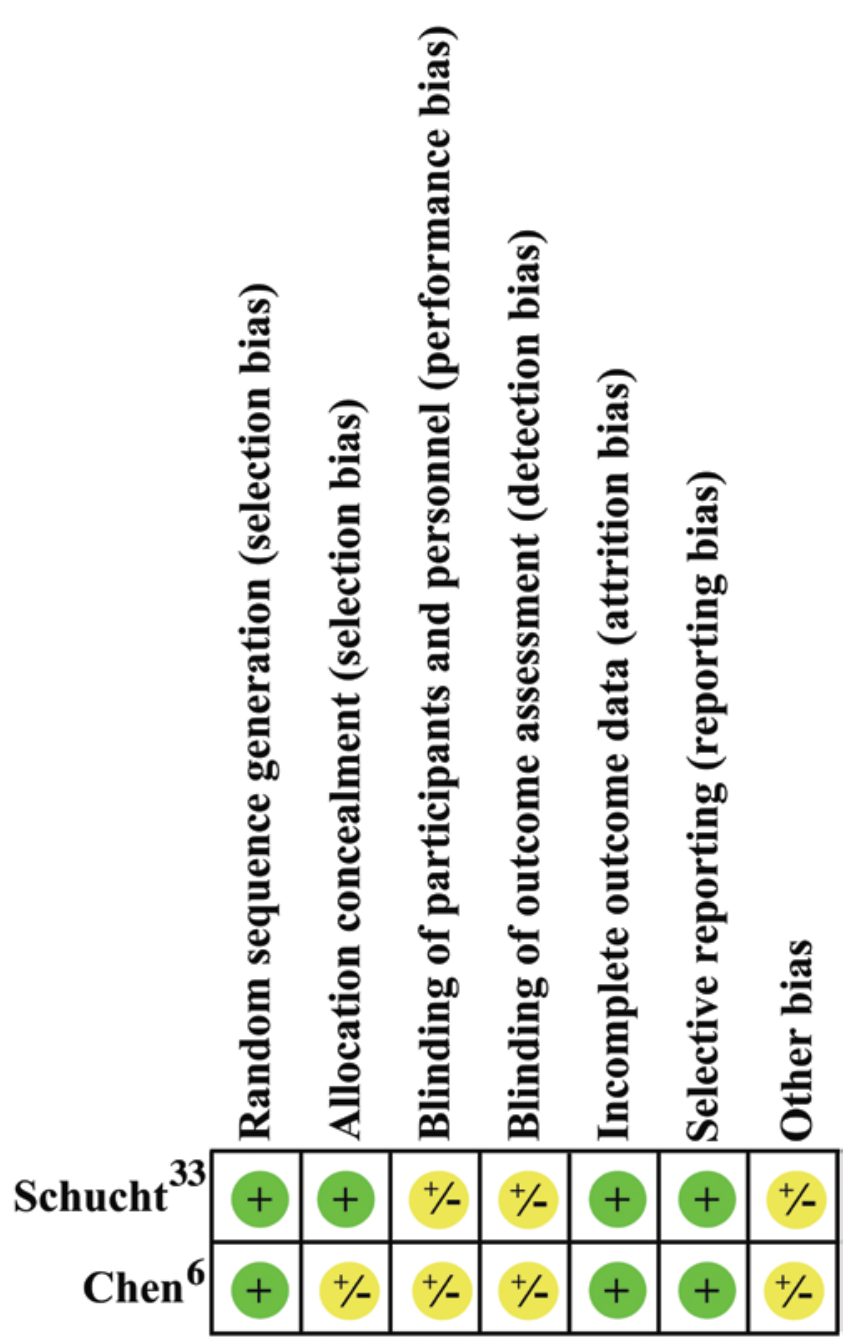

FIG. 2. Risk of bias summary graph of the included RCT studies. The green circles indicate that there is possibly a low level of bias, and the yellow circles indicate that the risk of bias is unclear. A red circle would symbolize a possible high level of bias.

by one, except for distal shunt failure (when the study by Roth et al. ${ }^{31}$ was excluded, $\mathrm{p}=0.03$ ) and operative time (when the study by Park et al. ${ }^{26}$ was excluded, $\mathrm{p}=0.01$ ).

\section{Publication Bias}

As shown in Fig. 5, the shapes of the funnel plots seem symmetrical and suggest that there was no publication bias in the current meta-analysis. These funnel plots indicated that bias from publications might not have a significant influence on the results of our meta-analysis.

\section{Discussion}

Our meta-analysis systematically summarizes the available evidence about outcomes of patients who underwent a laparoscopic method or a mini-laparotomy method for VP shunt placement. This meta-analysis shows that a laparoscopic method tends to produce better clinical outcomes compared with the mini-laparotomy method. Specifically, the distal shunt failure rate is lower, the operative time is shorter, and the blood loss is less in the laparoscopic group.

Distal shunt failure is defined as any distal catheter-related problem that requires a return to surgery for management, such as shunt malfunction, displacement, misplacement, malposition, dislocation, and obstruction. It is reported in case series to occur in $0 \%-15.7 \%$ of laparoscopically inserted peritoneal catheters ${ }^{1,5,6,9,13,20,35,37}$ and in $6 \%-28.7 \%$ of mini-laparotomy inserted catheters. ${ }^{18,28} \mathrm{In}$ this meta-analysis, the pooled data also show that the laparoscopic method significantly decreased the rate of distal shunt failure, which could be attributed to 2 main reasons, one being that the laparoscopic technique could prevent the distal shunt end from preperitoneal placement and confirm its efficacy simultaneously by direct vision. The other reason is that the laparoscopic method might prevent the peritoneal shunt end from obstruction if adhesiolysis is performed, especially in patients who have undergone abdominal surgery and formed peritoneal adhesions. ${ }^{23,24,31}$ However, a general surgeon performing laparoscopy will have more experience in dealing with adherences and distorted anatomy. ${ }^{24}$ This raises the question of whether the expertise of the general surgeon contributes to the reduced distal shunt failure rate. Inevitably, more or less influence on the veracity of our results might be due to the general surgeon's expertise. To avoid the influence of general surgeon, neurosurgeons should perform the laparoscopy portion in the future.

There was a significant difference in terms of the distal shunt failure rate between the 2 groups, but the significance disappeared when proximal shunt failure was also considered (Fig. 3), leaving a nonsignificant trend toward lower overall shunt failure in the laparoscopic compared with the mini-laparotomy group $(17.5 \%$ vs $20.7 \%$; $\mathrm{p}=0.53)$.

Infection is defined as the positive results of the wound secretion and CSF in laboratory reports. Studies have indicated that there is not a preferred surgical technique in terms of the overall infection rate between the mini-laparotomy method $(0 \%-1.3 \%)^{14}$ and the laparoscopic method $(0 \%-2.7 \%)^{20,30,35,36,39}$ Consistently, in terms of the overall infection rate, no significant difference was observed in our meta-analysis, but a trend in favor of laparoscopy exists. The fluctuation of the overall infection rate may be attributable to patient age, differences in antibiotic prophylaxis, ${ }^{18}$ number of surgeons, circulating personnel, and duration of the operation. ${ }^{17,30}$ There is no standard about which antibiotic should be administered and when to prevent infection.

Intraoperative complications were defined as accidental injuries to viscera during surgery. In this meta-analysis, no significant difference between surgical methods was observed. Corresponding with the result of meta-analysis, a similar result was obtained from the studies excluded from this meta-analysis in respect of intraoperative complications between the mini-laparotomy method $(0 \%-1.2 \%)^{18,28}$ and the laparoscopic method $(0 \%-1.9 \%) \cdot{ }^{10,13,15,36}$ One of the most important steps of laparoscopy is the establishment of pneumoperitoneum. It is obvious that an enlarged abdominal cavity can make the operation easier; thus, an expected result is that the laparoscopic technique prevents the abdominal viscera from immediate injury. Actually, most of the intraoperative complications occurred during 
TABLE 1. Characteristics of studies comparing laparoscopic and mini-laparotomy peritoneal catheter insertion.

\begin{tabular}{|c|c|c|c|c|c|c|}
\hline Authors \& Year & Country & Study Type & Group & No. of Patients & Mean Follow-Up in Mos (range) & Level of Evidence \\
\hline \multirow{2}{*}{$\begin{array}{l}\text { Schucht et al., } \\
\quad 2015\end{array}$} & Switzerland & RCT & Laparoscopic & 60 & 12.0 & $1 b$ \\
\hline & & & Open & 60 & 12.0 & \\
\hline \multirow{2}{*}{$\begin{array}{l}\text { Nigim et al., } \\
2014\end{array}$} & US & Retrospective cohort & Laparoscopic & 155 & $27.2(0-81.8)$ & $2 b$ \\
\hline & & & Open & 77 & $43.4(0-107.3)$ & \\
\hline \multirow{2}{*}{$\begin{array}{l}\text { Cohen-Inbar et } \\
\text { al., } 2014\end{array}$} & Israel & Retrospective cohort & Laparoscopic & 40 & - & $2 b$ \\
\hline & & & Open & 248 & - & \\
\hline \multirow{2}{*}{$\begin{array}{l}\text { Vybíhal et al., } \\
2012\end{array}$} & Czech Republic & Retrospective cohort & Laparoscopic & 67 & - & $2 b$ \\
\hline & & & Open & 325 & - & \\
\hline \multirow[t]{2}{*}{ Chen et al., 2012} & China & RCT & Laparoscopic & 26 & 3.0 & $1 \mathrm{~b}$ \\
\hline & & & Open & 26 & 3.0 & \\
\hline \multirow{2}{*}{$\begin{array}{l}\text { Raysi Dehcordi } \\
\quad \text { et al., } 2011\end{array}$} & Italy & Prospective cohort & Laparoscopic & 30 & 13.0 & $2 b$ \\
\hline & & & Open & 30 & 19.0 & \\
\hline \multirow{2}{*}{$\begin{array}{l}\text { Naftel et al., } \\
2011\end{array}$} & US & Retrospective cohort & Laparoscopic & 475 & 12.0 & $2 b$ \\
\hline & & & Open & 335 & 21.0 & \\
\hline \multirow[t]{2}{*}{ Park et al., 2010} & Korea & Retrospective cohort & Laparoscopic & 95 & $27.0(6.0-45.0)$ & $2 b$ \\
\hline & & & Open & 65 & $20.0(2.0-45.0)$ & \\
\hline \multirow[t]{2}{*}{ Argo et al., 2009} & US & Retrospective cohort & Laparoscopic & 258 & $10.5(0.0-46.7)$ & $2 b$ \\
\hline & & & Open & 321 & $17.0(0.0-48.7)$ & \\
\hline \multirow[t]{2}{*}{ Roth et al., 2007} & Israel & Retrospective cohort & Laparoscopic & 59 & 22.0 & $2 b$ \\
\hline & & & Open & 152 & 25.0 & \\
\hline \multirow[t]{2}{*}{ Bani et al., 2006} & Germany & Prospective cohort & Laparoscopic & 151 & - & $2 b$ \\
\hline & & & Open & 50 & - & \\
\hline \multirow{2}{*}{$\begin{array}{l}\text { Schubert et al., } \\
2005\end{array}$} & Germany & Prospective cohort & Laparoscopic & 50 & $11.0(0.2-31.0)$ & $2 b$ \\
\hline & & & Open & 50 & $18.0(0.2-42.0)$ & \\
\hline $\begin{array}{l}\text { Cuatico \& Van- } \\
\text { nix, } 1995\end{array}$ & US & Prospective cohort & Laparoscopic & 11 & 12.0 & $2 b$ \\
\hline
\end{tabular}

$-=$ not provided.

but not after the estimation of the pneumoperitoneum, ${ }^{31,33}$ and it is why there is no significant difference between the surgical techniques.

Operative time is defined as the duration from incision to suture. This time has been reported in case series as 49-78 minutes for laparoscopically inserted peritoneal catheters $^{13,20,39}$ and as 116-120 minutes for the mini-laparotomy method. ${ }^{16,30}$ Significantly reduced operative time in the laparoscopic group was also consistently observed in this meta-analysis. This reduction may be attributable to the simultaneous operation on the abdomen by additional general surgeons when the laparoscopic method is used. However, Schubert et al. reported an increased operative time for laparoscopy-assisted catheter placement. Further analysis showed that this increase is mainly due to the increased time needed for preparation of the laparoscopy instruments and coordination with general surgeons. ${ }^{32}$ Therefore, it may be that the operative time is further reduced as the number of cases increases and good collaboration takes place. Studies not analyzed in our meta-analysis revealed a different duration of hospital stay between

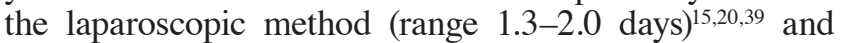
the mini-laparotomy method (range $4-8$ days). ${ }^{38}$ In this meta-analysis, a trend in favor of the laparoscopic method was observed; however, this trend did not reach statistical significance. The variation of duration of hospital stay in different studies might be attributable to patient selection. For example, some patients with carcinomas inevitably undergo further treatment in the hospital, thus prolonging the length of hospital stay. ${ }^{6,7,26}$ Additionally, it has been reported that laparoscopy surgery has advantages in reducing postoperative pain and shortening recovery time, ${ }^{19,21,34}$ thus, it might reduce the length of hospital stay.

Lastly, as revealed by this meta-analysis, a laparoscopic method could significantly reduce blood loss. Compared with the mini-laparotomy method, laparoscopic incisions are usually only $5 \mathrm{~mm}$, leading to less blood loss and improved cosmetic effect. ${ }^{23}$ However, raw data regarding the blood loss were insufficient; therefore, we could not draw a rigorous statistical result in terms of blood loss. This question needs to be addressed using more high-quality evidence.

Conversion to mini-laparotomy surgery is a risk of any laparoscopic procedure. Ochalski et al. ${ }^{25}$ converted $9 \%$ of minimal-access cases to open surgery because of extensive adhesions, rather than because of visceral or vascular injuries. Naftel et al. ${ }^{23}$ only converted to open surgery in $0.6 \%$ of laparoscopic cases. In each case, conversion was required because of dense adhesions; 2 of these 3 patients had undergone previous abdominal surgery. 


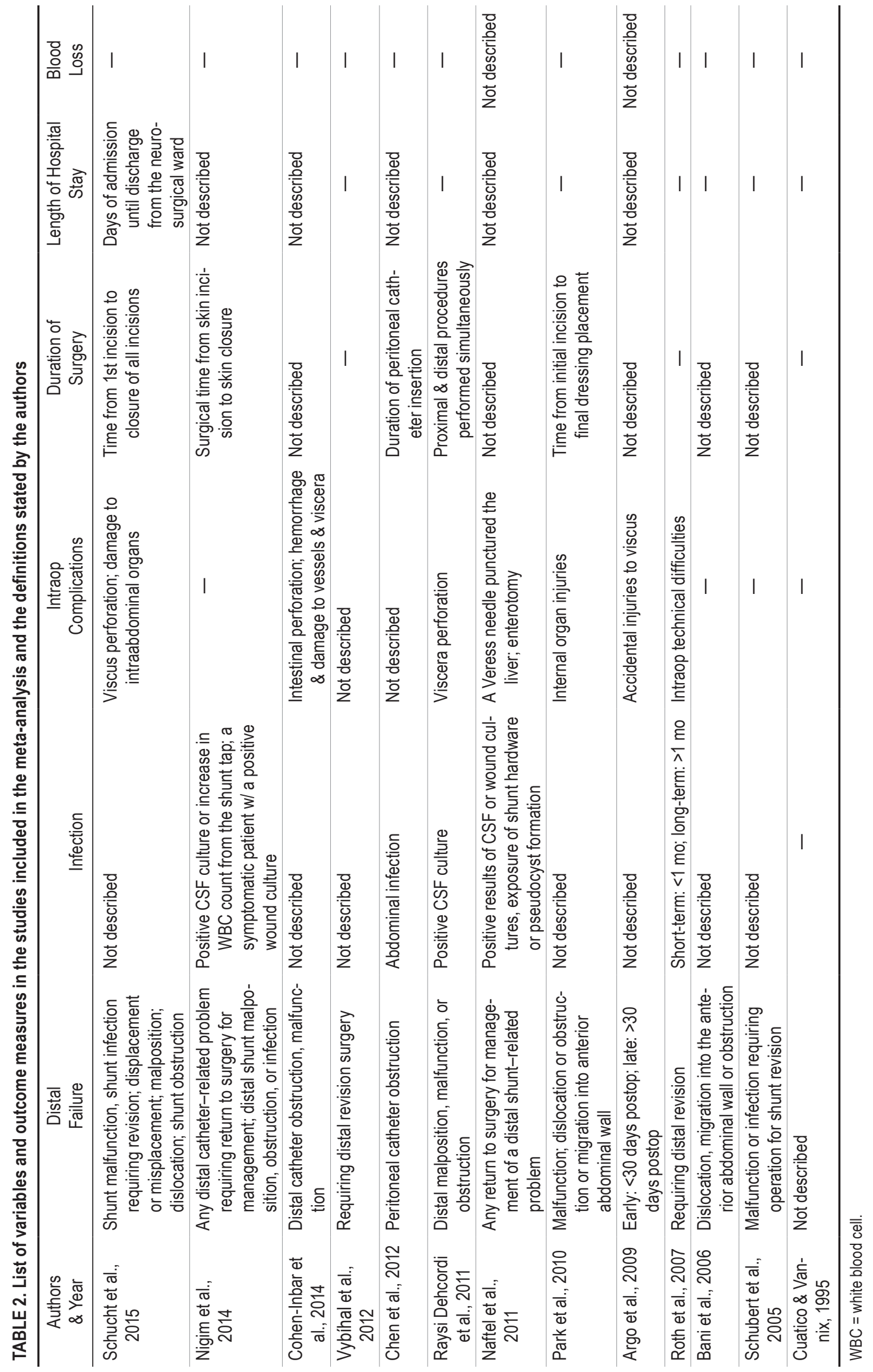




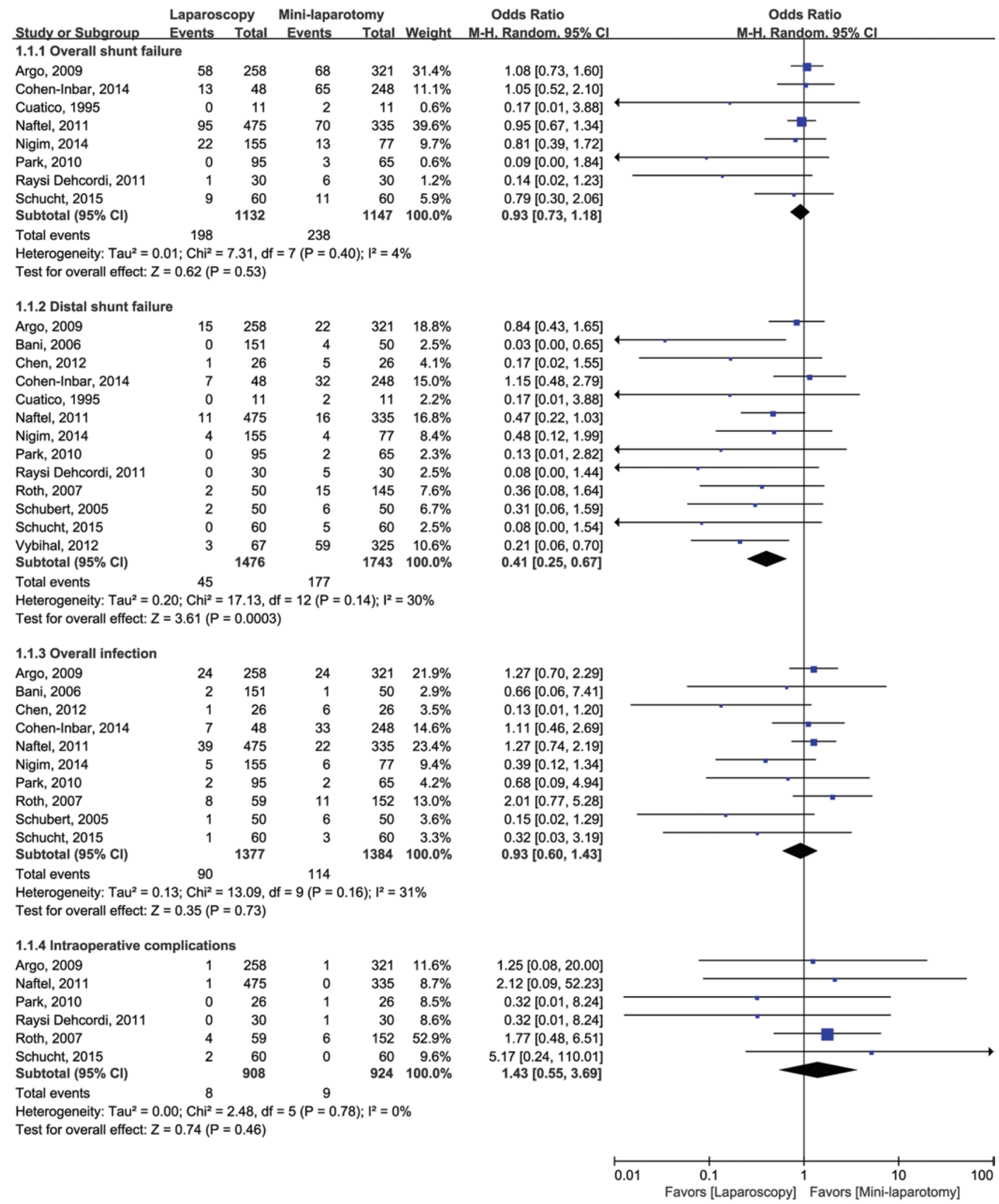

FIG. 3. Forest plot. Odds ratios of primary outcomes, including the incidence of overall shunt failure, distal shunt failure, overall infection, and intraoperative complications, evaluating the statistical difference between the laparoscopy and mini-laparotomy methods for peritoneal catheter insertion. Events refers to the number of patients and total refers to the number of patients. $\mathrm{M}-\mathrm{H}=$ Mantel-Haenszel. 


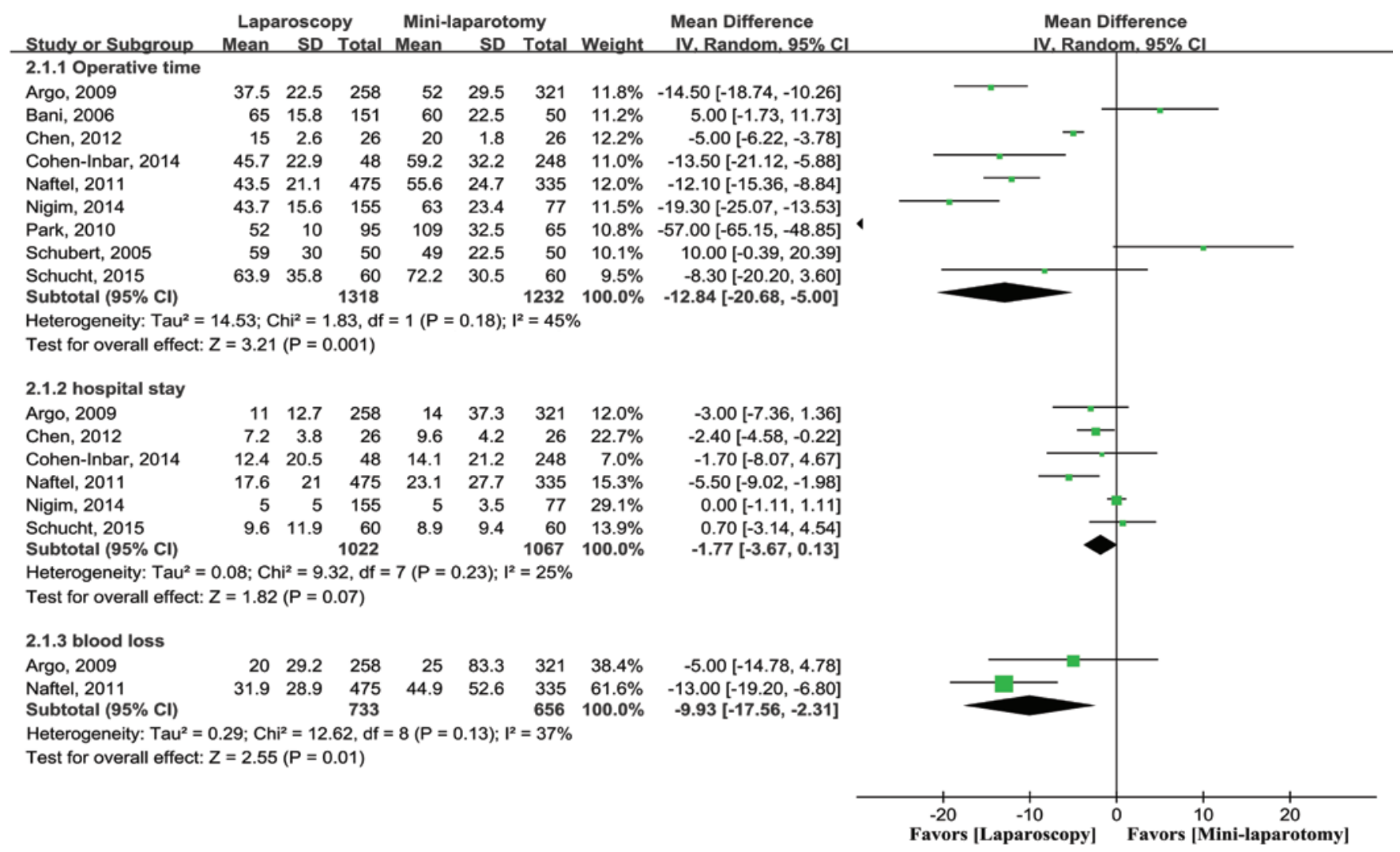

FIG. 4. Forest plot. Odds ratios of operative and hospital-related secondary outcomes, including the length of operative time, length of stay, and blood loss, evaluating the statistical difference between the laparoscopy and mini-laparotomy methods for peritoneal catheter insertion. IV = inverse variance.

\section{Limitations}

To draw a relatively reliable conclusion, we included as much evidence as possible by including RCTs and observational trials. Thus, there might be a selection bias. However, after weighing the pros and cons, we preferred to include more patients rather than exclude some studies, which might introduce bias. One other possible limitation comes from the neurosurgeons or general surgeons with different levels of experience. Furthermore, with the laparoscopic method, the peritoneal catheter insertion was

TABLE 3. Laparoscopic distal catheter insertion compared with mini-laparotomy distal catheter insertion for hydrocephalus

\begin{tabular}{|c|c|c|c|c|c|c|}
\hline Outcome & $\begin{array}{l}\text { No. of Participants } \\
\text { (no. of studies) }\end{array}$ & $\begin{array}{c}\text { Follow-Up } \\
\text { Duration (mos) }\end{array}$ & $\begin{array}{l}\text { Quality of Evidence* } \\
\text { (GRADE) }\end{array}$ & Relative Effect $(95 \% \mathrm{Cl})$ & $\begin{array}{c}\text { Absolute Risk } \\
\text { Reduction }\end{array}$ & $\begin{array}{c}\text { NNT } \\
(95 \% \mathrm{Cl})\end{array}$ \\
\hline $\begin{array}{l}\text { Overall shunt } \\
\text { failure }\end{array}$ & $2279(8)$ & $3-27$ & $\begin{array}{l}\text { High due to risk of bias, } \\
\text { large effect }\end{array}$ & OR 0.93 (0.73-1.18), $p=0.53$ & NA & NA \\
\hline $\begin{array}{l}\text { Distal shunt } \\
\text { failure }\end{array}$ & $3219(13)$ & $3-43.4$ & $\begin{array}{l}\text { High due to risk of bias, } \\
\text { large effect }\end{array}$ & OR $0.41(0.25-0.67), p=0.0003$ & $7.11 \%$ & $14(8-23)$ \\
\hline Overall failure & $2761(10)$ & $3-43.4$ & $\begin{array}{l}\text { Low due to risk of bias, } \\
\text { large effect }\end{array}$ & OR $0.93(0.60-1.43), p=0.73$ & NA & NA \\
\hline $\begin{array}{l}\text { Intraop compli- } \\
\text { cations }\end{array}$ & $1832(6)$ & $12-27$ & $\begin{array}{l}\text { Low due to risk of bias, } \\
\text { imprecision }\end{array}$ & OR $1.43(0.55-3.69), p=0.46$ & NA & NA \\
\hline Operative time & $2550(9)$ & $3-43.4$ & $\begin{array}{l}\text { Moderate due to risk of } \\
\text { bias, imprecision }\end{array}$ & $M D-12.84(-20.68$ to -5.00$), p=0.001$ & NA & NA \\
\hline Hospital stay & $2089(6)$ & $3-43.4$ & $\begin{array}{l}\text { Low due to risk of bias, } \\
\text { large effect }\end{array}$ & MD $-1.77(-3.67$ to 0.13$), p=0.07$ & NA & NA \\
\hline Blood loss & $1389(2)$ & $10.5-17$ & $\begin{array}{l}\text { Very low due to risk of } \\
\text { bias, large effect }\end{array}$ & MD $-9.93(-17.56$ to -2.31$), p=0.01$ & NA & NA \\
\hline
\end{tabular}

$\mathrm{NA}=$ not available.

* According to the Working Group grades of evidence. High quality: Further research is very unlikely to change our confidence in the estimate effect. Moderate quality: Further research is likely to have an important impact on our confidence in the estimate of effect and may change the estimate. Low quality: Further research is very likely to have an important impact on our confidence in the estimate of effect and is likely to change the estimate. Very low quality: We are very uncertain about the estimate. 

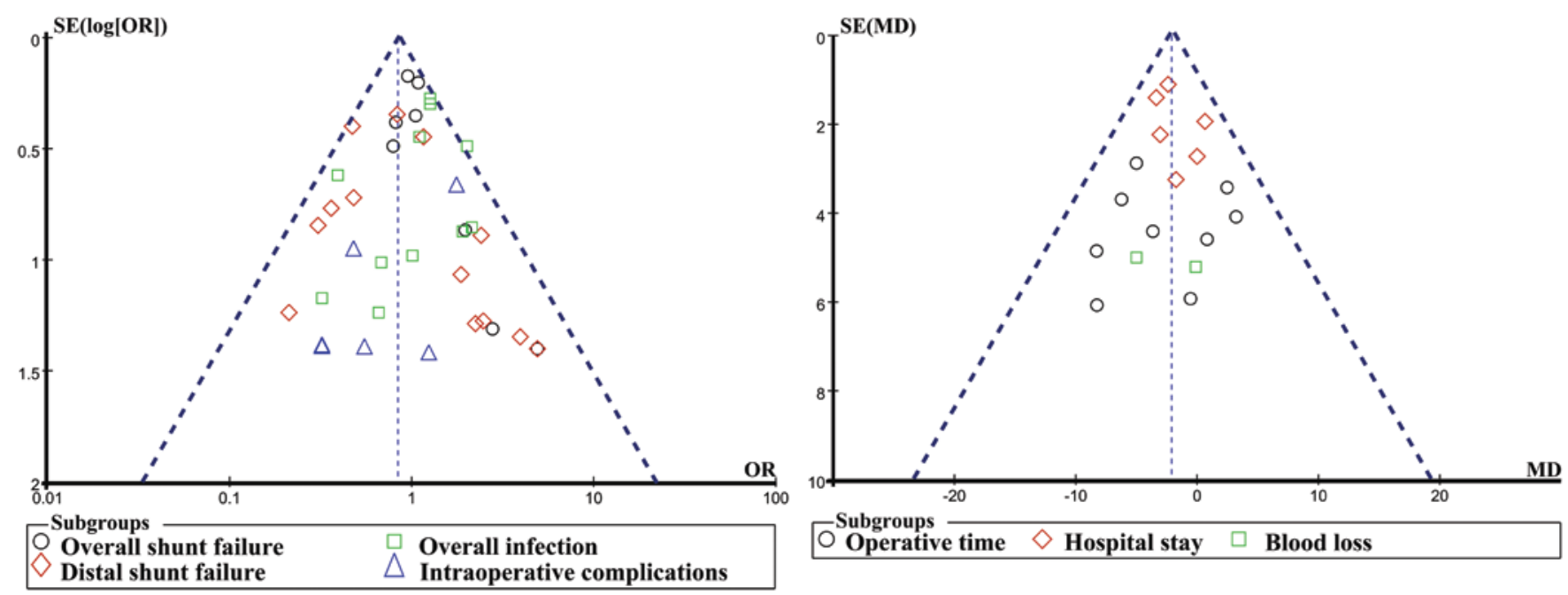

FIG. 5. Funnel plot analysis to detect publication bias. Funnel plots illustrating the meta-analysis of primary outcomes (left) and secondary outcomes (right). SE = standard error.

accomplished by general surgeons. In the future, well-designed RCTs are needed to confirm our conclusions.

\section{Conclusions}

The results of our meta-analysis clearly show that the laparoscopic technique is a safe, minimally invasive treatment option for the insertion of distal catheters. Laparoscopy can reduce the distal shunt failure rate and length of operation and might reduce blood loss, while not reducing the overall shunt failure, overall infection rate, and length of hospital stay and might not reduce intraoperative complications. The laparoscopic technique is a good option for the placement of peritoneal catheters; however, laparoscopy as a first-line treatment requires further research. In particular, data from multicenter and large sample studies and RCTs are needed.

\section{Acknowledgments}

This research was supported by grants from the Fundamental Research Funds for Guangdong Provincial Project of Science \& Technology (No. 2014A020212096) to A. Liu.

\section{References}

1. Abouhashem S, Taha MM, Ismail A, El Rashed M: Laparoscopic revision of the distally obstructed ventriculoperitoneal shunt. Turk Neurosurg 23:61-66, 2013

2. Ames RH: Ventriculo-peritoneal shunts in the management of hydrocephalus. J Neurosurg 27:525-529, 1967

3. Argo JL, Yellumahanthi DK, Ballem N, Harrigan MR, Fisher WS III, Wesley MM, et al: Laparoscopic versus open approach for implantation of the peritoneal catheter during ventriculoperitoneal shunt placement. Surg Endosc 23:1449_ 1455,2009

4. Bani A, Telker D, Hassler W, Grundlach M: Minimally invasive implantation of the peritoneal catheter in ventriculoperitoneal shunt placement for hydrocephalus: analysis of data in 151 consecutive adult patients. J Neurosurg 105:869-872, 2006

5. Carvalho FO, Bellas AR, Guimarães L, Salomão JF: Laparoscopic assisted ventriculoperitoneal shunt revisions as an option for pediatric patients with previous intraabdominal complications. Arq Neuropsiquiatr 72:307-311, 2014

6. Chen J, Liu C, Zhu H, Fu M, Lin F, Liu J, et al: [Laparoscopic ventriculoperitoneal shunt with temporary external drainage for hydrocephalus: a comparison with conventional ventriculoperitoneal shunt.] Nan Fang Yi Ke Da Xue Xue Bao 32:1836-1838, 1, 1840, 2012 (Chinese)

7. Cohen-Inbar O, Krausz M, Zaaroor M, Mahajna A: Laparoscopic implantation of distal peritoneal ventriculoperitoneal shunt catheter: a comparative study. J Neurol Surg A Cent Eur Neurosurg 75:392-397, 2014

8. Cuatico W, Vannix D: Laparoscopically guided peritoneal insertion in ventriculoperitoneal shunts. J Laparoendosc Surg 5:309-311, 1995

9. Farach SM, Danielson PD, Chandler NM: Diagnostic laparoscopy for intraabdominal evaluation and ventriculoperitoneal shunt placement in children: a means to avoid ventriculoatrial shunting. J Laparoendosc Adv Surg Tech A 25:151-154, 2015

10. Handler MH, Callahan B: Laparoscopic placement of distal ventriculoperitoneal shunt catheters. J Neurosurg Pediatr 2:282-285, 2008

11. Higgins JPT, Altman DG, Gøtzsche PC, Jüni P, Moher D, Oxman AD, et al: The Cochrane Collaboration's tool for assessing risk of bias in randomised trials. BMJ 343:d5928, 2011

12. Higgins JPT, Green S (eds): Cochrane Handbook for Systematic Reviews of Interventions Version 5.1.0 [updated March 2011]. London: The Cochrane Collaboration, 2011 (www.handbook.cochrane.org) [Accessed August 8, 2016]

13. Hong WC, Lai PS, Chien YH, Tu YK, Tsai JC: SingleIncision laparoscopic surgery (SILS) for ventriculoperitoneal shunt placement. J Neurol Surg A Cent Eur Neurosurg 74:351-356, 2013

14. Kanev PM, Sheehan JM: Reflections on shunt infection. Pediatr Neurosurg 39:285-290, 2003

15. Khaitan L, Brennan EJ Jr: A laparoscopic approach to ventriculoperitoneal shunt placement in adults. Surg Endosc 13:1007-1009, 1999

16. Khosrovi H, Kaufman HH, Hrabovsky E, Bloomfield SM, Prabhu V, el-Kadi HA: Laparoscopic-assisted distal ventriculoperitoneal shunt placement. Surg Neurol 49:127-135, 1998

17. Lazareff JA, Peacock W, Holly L, Ver Halen J, Wong A, Olmstead C: Multiple shunt failures: an analysis of relevant factors. Childs Nerv Syst 14:271-275, 1998 
18. Lund-Johansen M, Svendsen F, Wester K: Shunt failures and complications in adults as related to shunt type, diagnosis, and the experience of the surgeon. Neurosurgery 35:839844,1994

19. Marks JH, Kawun UB, Hamdan W, Marks G: Redefining contraindications to laparoscopic colorectal resection for high-risk patients. Surg Endosc 22:1899-1904, 2008

20. Martin K, Baird R, Farmer JP, Emil S, Laberge JM, Shaw K, et al: The use of laparoscopy in ventriculoperitoneal shunt revisions. J Pediatr Surg 46:2146-2150, 2011

21. Maurus CF, Schäfer M, Müller MK, Clavien PA, Weber M: Laparoscopic versus open splenectomy for nontraumatic diseases. World J Surg 32:2444-2449, 2008

22. Moher D, Liberati A, Tetzlaff J, Altman DG: Preferred reporting items for systematic reviews and meta-analyses: the PRISMA statement. BMJ 339:b2535, 2009

23. Naftel RP, Argo JL, Shannon CN, Taylor TH, Tubbs RS, Clements RH, et al: Laparoscopic versus open insertion of the peritoneal catheter in ventriculoperitoneal shunt placement: review of 810 consecutive cases. J Neurosurg 115:151-158, 2011

24. Nigim F, Thomas AJ, Papavassiliou E, Schneider BE, Critchlow JF, Chen CC, et al: Ventriculoperitoneal shunting: laparoscopically assisted versus conventional open surgical approaches. Asian J Neurosurg 9:72-81, 2014

25. Ochalski PG, Horowitz MB, Mintz AH, Hughes SJ, Okonkwo DO, Kassam AB, et al: Minimal-access technique for distal catheter insertion during ventricular peritoneal shunt procedures: a review of 100 cases. J Neurosurg 111:623627, 2009

26. Park YS, Park IS, Park KB, Lee CH, Hwang SH, Han JW: Laparotomy versus laparoscopic placement of distal catheter in ventriculoperitoneal shunt procedure. J Korean Neurosurg Soc 48:325-329, 2010

27. Patwardhan RV, Nanda A: Implanted ventricular shunts in the United States: the billion-dollar-a-year cost of hydrocephalus treatment. Neurosurgery 56:139-145, 2005

28. Puca A, Anile C, Maira G, Rossi G: Cerebrospinal fluid shunting for hydrocephalus in the adult: factors related to shunt revision. Neurosurgery 29:822-826, 1991

29. Raysi Dehcordi S, De Tommasi C, Ricci A, Marzi S, Ruscitti C, Amicucci G, et al: Laparoscopy-assisted ventriculoperitoneal shunt surgery: personal experience and review of the literature. Neurosurg Rev 34:363-371, 2011

30. Reimer R, Wharen RE Jr, Pettit PD: Ventriculoperitoneal shunt placement with video-laparoscopic guidance. J Am Coll Surg 187:637-639, 1998

31. Roth J, Sagie B, Szold A, Elran H: Laparoscopic versus nonlaparoscopic-assisted ventriculoperitoneal shunt placement in adults. A retrospective analysis. Surg Neurol 68:177-184, 2007

32. Schubert F, Fijen BP, Krauss JK: Laparoscopically assisted peritoneal shunt insertion in hydrocephalus: a prospective controlled study. Surg Endosc 19:1588-1591, 2005
33. Schucht P, Banz V, Trochsler M, Iff S, Krähenbühl AK, Reinert M, et al: Laparoscopically assisted ventriculoperitoneal shunt placement: a prospective randomized controlled trial. J Neurosurg 122:1058-1067, 2015

34. Schwenk W, Haase O, Neudecker J, Müller JM: Short term benefits for laparoscopic colorectal resection. Cochrane Database Syst Rev (3):CD003145, 2005

35. Shao Y, Li M, Sun JL, Wang P, Li XK, Zhang QL, et al: A laparoscopic approach to ventriculoperitoneal shunt placement with a novel fixation method for distal shunt catheter in the treatment of hydrocephalus. Minim Invasive Neurosurg 54:44-47, 2011

36. Stoddard T, Kavic SM: Laparoscopic ventriculoperitoneal shunts: benefits to resident training and patient safety. JSLS 15:38-40, 2011

37. Svoboda SM, Park H, Naff N, Dorai Z, Williams MA, Youssef Y: Preventing distal catheter obstruction in laparoscopic ventriculoperitoneal shunt placement in adults: the "falciform technique." J Laparoendosc Adv Surg Tech A 25:642-645, 2015

38. Tepetes K, Tzovaras G, Paterakis K, Spyridakis M, Xautouras N, Hatzitheofilou C: One trocar laparoscopic placement of peritoneal shunt for hydrocephalus: A simplified technique. Clin Neurol Neurosurg 108:580-582, 2006

39. Turner RD, Rosenblatt SM, Chand B, Luciano MG: Laparoscopic peritoneal catheter placement: results of a new method in 111 patients. Neurosurgery 61 (3 Suppl):167-174, 2007

40. Vybíhal V, Svoboda T, Procházka V, Benda P, Hanoun G, Smrčka M, et al: [Comparison of laparotomic and laparoscopic techniques for implantation of the peritoneal part of the shunt in the treatment of hydrocephalus.] Rozhl Chir 91:305-310, 2012 (Czech)

\section{Disclosures}

The authors report no conflict of interest concerning the materials or methods used in this study or the findings specified in this paper.

\section{Author Contributions}

Conception and design: Liu. Acquisition of data: He, Ouyang, Zheng. Analysis and interpretation of data: Liu, He, Ouyang. Drafting the article: Liu, He. Critically revising the article: Wang. Reviewed submitted version of manuscript: Zheng. Statistical analysis: Wang.

\section{Correspondence}

Anmin Liu, Department of Neurosurgery, Sun Yat-Sen Memorial Hospital, Sun Yat-Sen University, Yanjiang West Rd. \#107, Guangzhou 510120, China. email: liuanmin@mail.sysu.edu.cn. 